\title{
The Implementation of Sheltered Instructional Observation Protocol (SIOP) Model in Saudi Schools: A Study of EFL Teachers' Perspectives
}

\author{
Ahlam Aldakhil $^{1} \&$ Hind Alfadda $^{1}$ \\ ${ }^{1}$ King Saud University, Riyadh, Saudi Arabia \\ Correspondence: Ahlam Aldakhil, King Saud University, Riyadh, Saudi Arabia.
}

Received: February 3, 2021

Accepted: August 25, 2021

Online Published: August 30, 2021

doi: $10.5539 /$ elt.v14n9p67

URL: https://doi.org/10.5539/elt.v14n9p67

\begin{abstract}
The Sheltered Instructional Observation Protocol SIOP is a model designed to assist teachers in organizing and planning the lessons delivery through different stages. This model is also useful in enhancing the students' achievement and minimizing any chance of educational failure. However, EFL teachers need to be trained in order to guarantee successful implementation of this model. This study examined the implementation of the SIOP model from teachers' perspectives after they attended an introductory workshop in a private school in Riyadh city, Saudi Arabia. The study adopted the qualitative approach for collecting and analyzing the data. The sample of the study consisted of seven English language teachers ( 4 females \& 3 males). Two data collection instruments were used, namely, observational sessions and a semi-structured interview. Most of the researcher interaction with the sample was done online due to the outbreak of Covid-19 pandemic. The workshop and the interviews were done through Zoom video communication. The central findings of this study reveal that the majority of the teachers have covered all SIOP components during their lessons. Moreover, it was found that there is a relationship between the implementation of the SIOP model and the students' learning motivation. Furthermore, the results showed that the SIOP implementation might help in enhancing the teachers' proficiency. Besides, it was revealed that most of the teachers had a positive attitude towards the implementation of the SIOP model. However, they claimed that time and place might hinder any future implementation of the SIOP model. This study recommends a larger sample size, longtime study application and a life sample workshop to guarantee better results. It also provides significant implications which might be useful for EFL teachers, policy makers and interested researchers.
\end{abstract}

Keywords: English as a second language (ESL), English language learners (ELLs), Online learning, Sheltered instructional observation protocol (SIOP)

\section{Introduction}

To keep up with the world's globalization, learning English as a foreign language or alternative language has become crucial in several countries (Warschauer, 2000). A number of those countries use English not as a daily communication medium but rather as an essential means of learning to achieve academic and career success (Song, 2016). The main reason behind learning English language in these countries is also to access universities and companies where English is a major requirement (ibid). Furthermore, the Arab countries in general and Saudi Arabia in particular are among the countries in which learning English is vitally significant (Alrashidi \& Phan, 2015). In this regard, Alrashidi and Phan (2015) applauded that English is the only foreign language taught in Saudi schools.

Although learning English is a requirement in the Saudi schools, the students' proficiency level in English is almost low in schools (Alrashidi \& Phan, 2015). Consequently, the low proficiency level of Saudi students in school affects their achievement at the university level since they still did not reach the required level of proficiency. In this connection, it is claimed that EFL teachers are facing challenges to provide content knowledge and language activities for students with low proficiency level in English (Inceli, 2015). Hence, several educators highlighted the importance of the teacher's role in managing the classroom and providing students with the most effective strategies and tasks which contribute to facilitate learning English among students (Valle, Waxman, Diaz, \& Padron, 2013). The SIOP model is amongst the effective strategies which could assist in teaching English in schools. In fact, this model is designed to help teachers in the lesson planning 
and implementation as it enables the English language learners (henceforth ELLs) to achieve high level of proficiency (Echevarria, Vogt, \& Short, 2008). Therefore, this study is an attempt to investigate the implementation of this model from the EFL teachers' perspectives in Saudi Arabia. It also brings a fresh perspective to the Saudi Arabian educational field where no similar research has been conducted in corresponds to this model. This paper includes the statement of the problem, research questions, literature review, methodology, results, discussion, limitation and conclusion.

\subsection{Statement of the Problem}

Literature (e.g. Alrashidi \& Phan, 2015) reveals that the students' proficiency level in English is almost low in Saudi schools. Such low proficiency level of students affects their academic achievement at the university level. This puts those students under a serious pressure; their concerns usually lay in whether they are able to master the language and use it properly or not. Hence, teachers and researchers have come up with several important ways to help students master this language. One of the beneficial aspects that has been recently adopted in the educational field is the SIOP model which mostly focuses on enhancing the academic achievement of ELLS. Therefore, the objective of this study is to investigate the influence of the SIOP model on the teachers' practices at a private school in Riyadh city, Saudi Arabia.

\subsection{Research Questions}

The study aims to answer the following questions:

1) Which ones of the eight components of the SIOP model (lesson preparation, building background, comprehensible input, strategies, interaction, practice and application, lesson delivery, review and assessment) have the teachers implemented in their classrooms?

2) To what extent are EFL Saudi teachers aware of the SIOP model and its implementation?

3) Are the EFL Saudi teachers who attended the workshop willing to implement the SIOP model in the future?

\section{Literature Review}

\subsection{The Learning Needs of ELLs}

English Language Learners (ELLs) refers to "children or adults who are learning English as a second or additional language. This term may apply to learners across various levels of proficiency in English" (Laney, 2011). The needs of the learners lay in two types; one is the cognitive demands and the other is the linguistic demands (Kareva \& Echevarria, 2013). Those demands need to be taken into consideration when teaching ELLs so as to provide them with the best knowledge. Hence, the number of English language learners is growing in Saudi Arabia (Al Fadda, 2020). Yet, their academic proficiency level is showing no progress (Al Fadda, 2020). It is suggested that the usage of the SIOP model will significantly enhance the ELLs academic performance (McIntyre et al., 2010).

\subsection{The SIOP Model Overview}

Jana Echevarria, Marry Ellen Vogt and Deborah J. Short have proposed the SIOP model to help enhance the students' achievement and minimize any chance of educational failure (Echevarria, Short, \& Powers, 2008). The SIOP is designed to help teachers in organizing and planning the lessons delivery through different stages (İnceli, 2015). It aims to increase the students' achievement through the content areas (Short, Echevarria, \& Richards-Tutor, 2011). Through using the SIOP model, teachers can be able to systemically organize the lesson and avoid possible classroom challenges (ibid). Every part of the SIOP model cannot be effective unless there is a successful teaching scenario (Otway, 2007). It is composed of eight components, namely, lesson preparation, building background, comprehensible input, strategies, interaction, practice and application, lesson delivery, and review and assessment. Lesson preparation focuses on how to direct the classroom instruction (Inceli, 2015). Building background concentrates on the connection the teacher makes to the student background experiences and prior learning in addition to focusing on the students' academic vocabulary (Al Fadda, 2020). Echevarria \& Vogt (2010) contended that comprehensible input focuses on the importance of the teachers' role to deliver a clear speech, an understandable variety of academic activities and examples to increase students' comprehension. Moreover, strategies allow teachers to have a chance in explaining learning techniques for students and use information effectively (Echevarria, Vogt, \& Short, 2008). Through interaction, students can learn conversational and academic language simultaneously with their peers and teachers (Kareva \& Echevarria, 2013). Teachers who use SIOP usually focus on the importance of applying different activities that encourage students to participate in understanding the content as well as the language skills they are supposed to learn (Kareva \& 
Echevarria, 2013). In lesson delivery, teachers are eager to plan the lesson in a way which helps meet the students' level, time and objectives (Inceli, 2015). Review and assessment in the SIOP model include key language concepts and students' comprehension evaluation apart from providing teachers' feedback on the students' performance (Inceli, 2015).

\subsection{Previous Studies}

Vidot (2011) conducted an evaluative case study regarding the efficacy of the SIOP model in mathematics instruction for English language learners. The aim of Vidot's study was to identify the extent to which the implementation of SIOP model can influence the mathematics instruction in a mid-sized rural high school. In addition to the SIOP model, there were two different mathematics methods combined along with the SIOP model in order to enhance the students' outcome. However, during the interviews, Vidot found that most of the teachers expressed their preference to the SIOP model in contrast to the other methods. Besides, the classroom observations showed the effectiveness of the SIOP implementation.

Moreover, Koura and Zahran (2017) examined the impact of the SIOP model on student teachers' teaching skills and self-efficacy. They found that the experimental group outperformed the control group in all the components of the SIOP model except three components, namely, lesson preparation, comprehensible input and interaction. Furthermore, the control group lacked a number of important factors regarding teacher effectiveness which are: giving feedback, providing instruction, praising the students, linkage to the students' background, and using activities. In contrast to the experimental group, the results obtained from the control group showed a gradual development in the teachers teaching skills and self-efficacy at the end of the program.

Meza (2010) also examined the impact of teacher responsiveness to the implementation of the SIOP model among three different high schools in Harrisonburg city. The study found that teachers are willing to make the most needed changes in order to implement the SIOP model. In addition, there are some teachers who have heard about this model but never used it. On the contrary, other teachers claimed that they had never heard about it and a few of them applied only parts of the model. However, even if teachers are aware of the benefits of SIOP model, surprisingly they feel that there was huge pressure on them if they decided to apply it in that they have no time and they are not trained to use it in all means.

To add more, Ray (2011) evaluated one-year implementation of the SIOP model in a specific high school. The data in his study were collected from randomly volunteered teachers. The results showed that the teachers often applied all the eight components of the SIOP model. Besides, most of the teachers agreed that the SIOP model improved the students' achievement. Eventually, one third of the teachers stated that they would use the SIOP model in the future where $41 \%$ of them declared that they would use it most often.

Finally, Alfadda (2020) has recently evaluated the implementation of the SIOP model from the Saudi English language teachers' perspectives. The researcher used a descriptive design study for a sample of 300 male and female teachers. The findings of the study concluded that several aspects might affect the implementation of the SIOP model in the Saudi schools. These aspects include the educational qualification, career status, job experience and training courses. On the other hand, the results of the study emphasized that the classrooms at the school level in Saudi Arabia are beneficially equipped with technical, financial capabilities to implement the SIOP model successfully. The researcher also indicated that EFL Saudi teachers are qualified enough to implement the SIOP model in Saudi Arabia.

\section{Methodology}

This section highlights the methodology of the study. It discusses the study design, population and sampling of the study, data collection instruments and procedures of the study.

\subsection{Population and Sampling}

The population of the study included all English language teachers at a private school in Riyadh, Saudi Arabia. However, seven of these teachers were selected as the sample of the study. This sample was selected through convenience sampling technique in which the participants were selected based on their willingness to take part in this study. The study was mainly conducted online, where the researcher meets the participants via an application platform called Zoom due to the outbreak of the Covid-19 pandemic. All the participants in this study were English language teachers and are native speakers of Arabic and English for them is considered to be a foreign language. Their age also ranged from 31 to $50(\mathrm{M}=38)$ while their teaching experience ranged from three years to 30 years.

In terms of the subjects that the participants teach, two teachers declared that they taught English only. Three other teachers indicated that they taught social studies for one year. Besides, another teacher taught social studies 
and math, and the last teacher taught science and math at elementary schools. It is noticed that the differences between the grades that the teachers taught. These school levels range from grade 4 to grade 12 . This difference will be useful in that the teachers' perceptive regarding the SIOP model will represent their views for different school levels.

\subsection{Instruments}

In order to establish validity, the researcher designed a mixed-method data collection framework, which includes two different data collection instruments, namely, an observation session for four classes and a semi-structured interview with seven English language teachers. In fact, using more than one data collection instrument to examine a certain phenomenon contributes to reducing bias and increases the validity of the instruments as well as the credibility of the study (Fraenkel, Wallen \& Hyun, 1993; Patton, 2002). The semi-structured interview contained three main sections and 26 questions. Each interview took approximately 15 to 30 minutes.

\subsection{Validity of the Instruments}

The obtained data of the interviews were transcribed and coded. In this regard, Linneberg and Korsgaard (2019) argued that coding the qualitative data makes it ready and easy to read and access for further analysis. Moreover, it increases the quality of the data and findings. Subsequently, the interview data were member checked; this technique was proposed by Lincoln and Guba (1985) who claimed that " it is the most crucial technique for establishing credibility" (as cited in Meza, 2010: 314). Besides, this technique allows the researcher to ask the interviewees to revise and edit the interviews' transcription to determine the accuracy and credibility of the results (Creswell \& Poth, 2016). As for the current study, the interview transcriptions were sent to the participants via email to add more credibility to this study. All interviewees were asked to review their transcriptions and add or clarify any ideas. All of the interviewees replied to the researcher making few amendments to the transcriptions of their interviews. For instance, one of the participants asked for minor changes, including removing the "ums" and clarifying some ideas presented in the interview. All amendments and comments of the interviewees were taken into consideration, and the transcriptions were modified accordingly.

\section{Results}

This section provides the analysis of the data obtained from the observational sessions as well as the interview. This analysis is intended to answer the questions of the study. Before conducting the interviews with the participants, the questions were prepared in a way which help achieve the objectives of the study. The teachers were also asked to describe their students' proficiency level in general. Their answers were almost similar to each other in that the majority of them agreed that their students level varies to a certain extent. The answers regarding the students' proficiency were as follows:

"My students' proficiency level actually varies from one section to another, also from one student to another.... I am teaching three sections this year and two of them are very good. However, the students' proficiency level in the other section is acceptable" [Teacher A]. "I can say that 65\% of my students are good in English in terms of spoken and expressing themselves while their proficiency level in the other skills varies to a certain extent" [Teacher B]. ".... if I am going to pass a general judgment here in Saudi students, I can say that they are generally good when it comes to speaking English .... Generally, their proficiency in reading is low and thus this needs more attention from EFL teachers in Saudi Arabia" [Teacher D].

\subsection{The Teachers' Implementation of the Eight Components of the SIOP Model}

This section highlights the extent to which the EFL Saudi teachers adopt the eight components of the SIOP model in their teaching.

\subsubsection{Analysis of Observations}

According to the researcher's observational notes during the classes, it was revealed that the majority of the teachers covered almost all of the SIOP components. Yet, one of the most neglected components was the lesson objectives where the lesson in one of the observed classes started immediately without reading the objectives to the students or even displaying it on the screen. Another component that was hardly implemented is the connection between the lesson and the students' personal background. During all four observational sessions, it was noticed that the EFL teachers do not link the lessons to the students' background. On the other hand, the teachers were extremely eager to deliver a comprehensible input to their students. Furthermore, the researcher also noticed a variety of strategies that were applied by the teachers to motivate the students and guarantee better delivering of the lesson. In general, the teachers have covered almost most of the SIOP components. However, there are some misconceptions regarding the background, review and assessment elements. 


\subsubsection{Analysis of Interviews}

One of the questions of the interview was related to the extent to which the participants take into consideration defining the lesson objectives to the students. The majority of the teachers answered that they think that defining the lesson objectives to the students is an essential component of lesson delivery.

"Yes, sure." [Teacher A]. "Sure, 100\%. If they do not know where they are going, this is the problem" [Teacher B]. "... of course in the objectives when I start the class. I write like a title okay, and there will be objectives, the content objectives itself and concept objectives which is related to the let's say to the story you know because in the story it has the skim like cause and effect sometimes of the purpose sometimes it has compare and contract so this scale will be explained in the objectives and in return will be displayed and discussed like in a few minutes in the beginning.... there is will be a scale about the language." [Teacher C]. "I do yes." [Teacher D]. "Definitely I must do that whenever I start my lesson, it must be done." [Teacher E]. "Of course, I always share with them my objectives at the begging of the lesson, for them to know what they are going to take during the whole lesson.... And sometimes when I forget to do this, they ask me about the objectives" [Teacher G].

However, only one teacher indicated that he sometimes clarifies the lesson objectives to his students before starting the lesson but not all the time: "Usually but not all the time, I clarify the objectives and make them clear to the students, not necessarily by telling them you have to master this in class. At least, they know what they should do" [Teacher F].

After that the teachers were asked to clarify whether they consider their students' age and level during the preparation of the lesson, the teachers' answers were in favor of applying this aspect except the answer of teacher C. One of the teachers also referred to the importance of individual differences to meet the students' interest, cultural background, and nationality and religion in the same time. Another teacher suggested that during this semester and since it is an online learning which is a new experience to the students, teachers must consider the individual differences among the students so as to reach better outcome. Furthermore, one of teachers indicated that she takes customization into consideration when she feels that the content is beyond the students' level. Similarly, another teacher declared that she does her best to make the content easier to her students.

"Definitely, this is one of the most important things that I try to focus on..... I try to choose texts that... are suitable to the students age, interests, that goes fine with our cultural background you know being Saudis and Muslims" [Teacher D]. "Yeah, I make sort of customization to the content...... So usually when I feel that it is way beyond their level, I have to make such of customizations" [Teacher F]. "Yeah of course, I try to choose something that suits them in ... their level. Even if the text is very complicated or it has very difficult words, I try to make it a lot, a little bit easier to suit their level" [Teacher G].

On the other hand, only one teacher indicated that he sometimes takes the students' level and age into consideration. He explained that the reason behind that is the insufficient time in which teachers focus on the differences among students.

Moreover, the teachers were asked if they were using additional materials to guarantee better delivering of the lesson. In this case, all teachers agreed on the importance of using extra materials to enhance their lesson delivery. For example, teacher A emphasized the importance of integrating different martials specifically during the virtual learning. Similarly, teacher B indicated that the teacher must touch upon the students' creativity to think out of the box. Furthermore, teacher $\mathrm{C}$ mentioned the usage of online martials for this semester and during the normal circumstances in that the usage of worksheets and games is useful. Teacher $\mathrm{F}$ also suggested different platforms and online websites to help teachers in delivering the lessons. Besides, teacher $G$ stressed the importance of PowerPoint presentations and videos. However, teacher E answered that she made use of additional martials a lot. Teacher $\mathrm{D}$ also suggested the usage of different resources to support her lesson delivery such as choosing different texts and worksheets.

Another question was directed to the participants regarding the linkage between the students' personal background and the lessons. Five of the teachers answered that they make sure that the lesson content is connected to the students' background. For example, teacher A indicated that as teachers "we have to reflect on real life situation" Moreover, Teacher B explained that there is a part of the lesson preparation called "connecting objectives with real live situations". Furthermore, teacher C focused on the importance of doing so while teacher D indicated that the students' background is an essential factor for preparing the lessons. Finally, teacher E answered that "connecting the students' personal background with lessons is a must". However, participants $\mathrm{F}$ and $\mathrm{G}$ emphasized that they sometimes focus on the students' background. 
In addition, the participants were asked if they try to connect the students' past knowledge with the new information presented to them. The majority of the participants indicated that connecting the past knowledge with the new information is important to their students. To explain more, participant A stated that "these are from the basics of preparing a lesson". As for participant $\mathrm{B}$, he referred to it as the prior knowledge. Besides, participant D stressed the importance of focusing on the prior knowledge while participant $\mathrm{E}$ stated that the students' background knowledge will help in figuring out where to begin in the content. Participant $\mathrm{G}$ also indicated that she examines the students' background knowledge by asking them questions about the present topic. As for participant $\mathrm{C}$, he pointed out that he feels lucky regarding this point since he is teaching his former students and this gives him the advantage of knowing their educational background.

"Yes of course, that is one of the most important points we have to do inside the class.... One of the advantages that I have is that in this semester is that I am teaching the same students I taught last year so I know the background of the students" [Teacher C]. "The prior knowledge is defiantly taken into consideration..... I definably think of the ways of connecting what they already know i.e. their prior knowledge and the new information" [Teacher D]. "Definitely, it will tell me where to start and because of it I do not have to repeat a lot of information" [Teacher E]. "In terms of prior knowledge and their background information, I ask them questions like "Did you read about this? Do you know any information about this? Did you ever watch a movie that has this part of information?" [Teacher G].

On the other hand, participant F stated that he sometimes connects the students' past knowledge with the new information presented to them.

Regarding the importance of using an appropriate type of speech such as the tone and the vocabulary to suit the students' level, all participants agreed on the significant role of the type of speech and tone in their lessons. For example, teacher A pointed out that in order to deliver your lesson effectively, a suitable tone must be used. Participant B mentioned that it could be challenging in a way or another during the virtual class, yet he does his best to cover it. Additionally, the participant $C$ explained that this is an important factor especially when the teacher is dealing with students who vary in their English proficiency level. As for participant D, her strategy is to group her students based on their level to address them with the right tone and vocabulary. The participant's D answer was "yes, definitely". Furthermore, participant $\mathrm{F}$ indicated that he sometimes notices that he has to adapt his tone and the vocabulary during the lesson so that he can act according to such a tone. Finally, participant $G$ declared that she is very good when it comes to manipulating her tone and type of speech.

"Yeah sure actually, it is a very big challenge especially online in virtual classes; I sometimes mime or give gestures while delivering a class.... we need to use a different type of language to touch upon all students' levels and to get like the most feedback of them" [Teacher B]. "Yes, of course. It is very important; When I communicate with my students, I need to change my tone with them by producing a variety of vocabulary..." [Teacher C]. "Defiantly, ... I need to target you now a certain level of students or category of students and I have to use a different tone, use a different vocabulary and different terminologies" [Teacher D]. "Yes, of course. And sometimes I figure it out during the class, so I have to simplify the questions in order for them to understand" [Teacher F]. "Of course, this is what I am very good at, especially in real teaching and online teaching.... I know when to raise my voice.... I do not use very complicated vocabulary; I just use the suitable vocabulary" [Teacher G].

The participants were asked what they will do to guarantee better delivering of the lesson. Most of the participants' claimed that they do this by using different types of questions, quizzes or any kind of assessment. As a result, the students answer to these questions or quizzes will determine whether they could build a clear idea about the lesson or not.

One of the important components of the SIOP model is the usage of strategies to deliver the lesson. Hence, the participants were asked about the strategies they use to deliver their lessons in the class. The teachers' responses regarding this issue varies; for example, participant A maintained that they should use a wide range of strategies in that such strategies can motivate their students to learn and engage in the lesson. Furthermore, participant B thinks that strategies must be applied according to the students' level and interest claiming that not all strategies are suitable to every lesson or even a student. By the same token, participant D explained that students differ in many aspects and that is why we need to use a variety of strategies. According to participant $\mathrm{C}$, the use of strategies is a must and during the online learning, he would guarantee that every student will have a role in the lesson; as for the actual classes, he will depend mostly on grouping the students. Participant $F$ believes that the most important strategies are the ones which focus on the use of the cooperative learning and effective learning; such strategies are useful as they make students the center of the learning process. 
However, participant $\mathrm{E}$ indicated that she sometimes focusses on the use of strategies. As for participant $\mathrm{G}$, she showed some concerns regarding using strategies during this semester due to the online learning where not all strategies work, yet she thinks it is an important part of the learning process.

To add more, the participants were asked if they think that the students' interaction plays a huge role in the lesson or no. In this connection, all teachers are in favor of the students' interaction in the classroom. Participant A also believe that the students' interaction is a sign of the students' satisfaction of the teachers' methods of teaching and that they comprehend the knowledge presented. As for participant B, he declared that students' interference is an essential aspect specially in virtual classes. Similarly, participant $\mathrm{C}$ mentioned that the students' interaction is considered as the center of the teaching-learning process. Participant $\mathrm{D}$ also indicated that the level of the students' engagement in the class determine whether the lesson was successful or not. Furthermore, participant $\mathrm{F}$ emphasized that the students' involvement and interaction play a huge role in the lesson comprehension. According to participant G, the teacher is the one who is responsible for the students' interaction.

"Yes defiantly, of course when students interact with the teacher, this is a very clear indication that they love the teacher; secondly, they understand what the teacher is teaching, and thirdly they are very much interested in participating in the class activities" [Teacher A]. "Since the online or the virtual classes we need like interference to facilitate the job or the student work; but in general my philosophy is .... the class should be student-centered. Otherwise, the teacher will fail to deliver the lesson successfully" [Teacher B]. "Defiantly... One of the most important elements that we use to evaluate the teachers' performance is the level of engagement that her students have... if the students are engaged, it is a successful lesson; if the students are not, then the lesson will need a lot of presentation and explanation" [Teacher E]. "I believe that the students' interaction is the center of the teaching-learning process in my classrooms. I try new ways to increase the student's interactions and engagement too in order to make sure that students are playing their roles during the lesson" [Teacher C]. "Of course, if they are not feeling involved and they do not interact with the content that is being displayed, this means that there is a problem in one area..." [Teacher F]. "Of course, ...The teacher is the one who makes the students either interact or just sit, listen or daydream about something else" [Teacher G].

Moreover, the participants were asked if they would allow any practicing of the students' first language? The participants' responses vary according to their beliefs and the school's policy. As for teacher $\mathrm{C}$ he indicated that his school insists on using English only in the classroom. However, he sometimes tries to explain the abstract objectives to the students by translating it, and if the students communicate between each other in Arabic it is fine by him as long as they speak loudly in English. As for participant A she said that she does not like it when the students talk in Arabic between each other, yet she allows it only if they use English when participating. Also, participant F point out that using Arabic is prohibited but sometimes students who are below the level might tend to use Arabic which is fine as long as they have a clear idea about the lesson. Similarly, participant G indicated that mostly weak students will use Arabic during the lesson. However, she will replay to them in English. Regarding the student communication in Arabic between each other, again she does not mind it as long as they answer in English.

"...I have noticed that when the students are in the same group, they start talking in Arabic to each other, also using this chat language, so I do not like this at all but I do not know they are not with me they are not in front of me... that you have to use English..." [Teacher A]. "our school insist that the teachers must speak English and no one speak a single word in their language... So, using the language is to be used hardly rare... oh, they do it always all the time I do not have any problem with that. But they will answer the question in English" [Teacher C]. "...it is prohibited but you know sometimes, especially with lower grades... they cannot grasp the lessons especially the meanings of some words and thus these could be explained in Arabic to make the picture clear to them..." [Teacher F]. "...students sometimes answer questions in Arabic or they sometimes forget, and speak Arabic. But then, I answer back in English... some girls speak in Arabic when we do the group work" [Teacher G].

On the other hand, participant E pointed out that she will not allow any other language in her class and if they speak in Arabic, she will pretend not to understand them and more seriously they might lose marks! Furthermore, participant $\mathrm{D}$ mentioned that it is not acceptable to communicate in the first language, and the same applies to their communication between one other during the group work. Participant B argued that when students are struggling to answer in English, he asks them to communicate to one of their friends by using a mobile application (since the class are online these days) and to translate their answers so that they can answer the question in English. 
One of the most important components of the SIOP model is the students' practice of knowledge. Therefore, the participants were asked whether they focus on their students' practice and application of knowledge. Their answers were all similar and in favor of the importance of the students' practice and application of the content. Participant A, for example, pointed out that she focuses on the students' practicing in general and on the low achievers in particular. Moreover, participant B indicated that he sees knowledge practicing as an essential part of the students' learning. He indicated that his students ask him why they study poetry; they do not want to take it as a job in the future. Hence, his answer was that you can be both: having a decent carrier and being a poet in the same time such as Dr. Alqusaibi (a Saudi business man, a minster, and a poet in the same time). As for participant $\mathrm{C}$, he declared that he tries to prepare a number of questions and practices to involve his students in the lesson. Participant $\mathrm{D}$ also pointed out that she examines her students practicing of the knowledge by several summative assessments to know what skills they mastered or where she went wrong as a teacher. Similarly, participant $\mathrm{E}$ indicated that during the students' practice, she can figure out whether they mastered the skills presented to them or not. Besides, participant F explained that there are several ways to examine his students' application of the knowledge and he recommend activities and gamification as an involvement and interested tools to the students. To add more, participant $\mathrm{G}$ mentioned quizzes as a tool to examine the students' application of the knowledge.

Furthermore, the participants were asked to suggest anything they will do to support their lesson delivery. Their answers are indicated in the figure below.

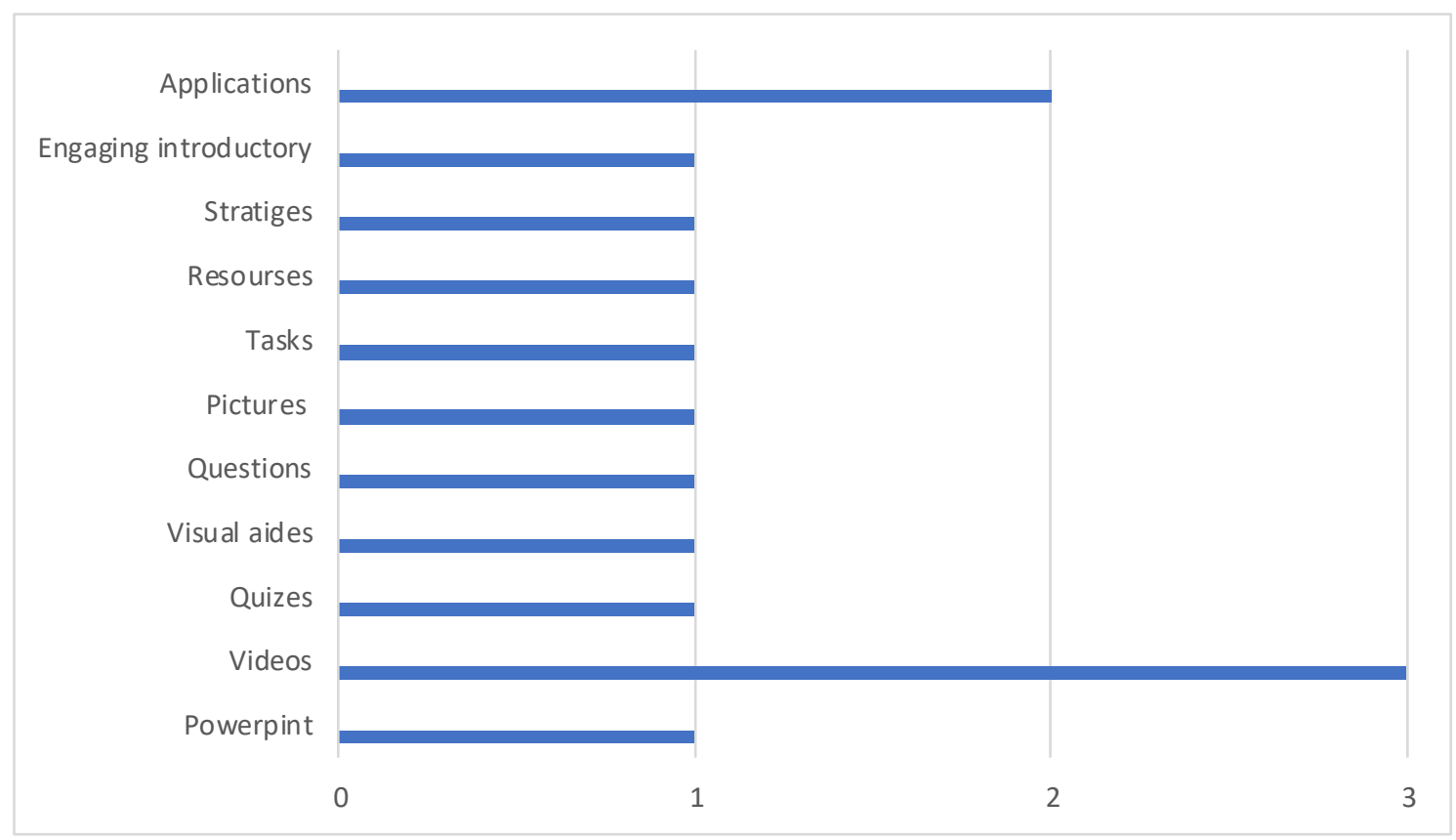

Figure 1. The participants' suggestions to support their lesson's delivery

Last but not least, the participants were asked if they believe of the importance of reviewing and assessing their students which is the last component of the SIOP eight components. The participants agreed on the importance of reviewing and evaluating their performance and their students. For instance, participant A focuses on reviewing her students' past knowledge before starting the class. Moreover, participant B claimed that he assesses his students at the end of the class. Participant $\mathrm{C}$ declared that the assessment of students is important for the students' future. Similarly, participant D stated that " it is very important". Furthermore, participant E mentioned that she put in mind the type of assessment she is going to apply during the lesson preparation. Participant $\mathrm{F}$ emphasized that it is a part of the educational process. Finally, participant $\mathrm{G}$ declared that by assessing and reviewing the students' knowledge, the teacher will be able to determine if the students understand the lesson or she/he needs to study it again.

\subsection{The Teachers' Knowledge Regarding the SIOP Model}

\subsubsection{Analysis of Interview Data}

In this part, the researcher analyzes the data of the last section of the interview. The participants were asked if they think that their classroom environment is suitable for the implementation of the SIOP model. Their 
responses varied regarding the possibility of applying the model in their classroom. For instance, participant A thinks that her classroom is equipped enough with all the materials needed to implement the SIOP model. According to participants B, C, and D, the SIOP model is almost similar to what they are already applying with their students. Therefore, their classrooms are suitable for the implementation of the model.

"Well for me it is pretty much... equipped with all the necessary things that the teacher needs in a class so I think that is yes, it is qualified." [Teacher A]. "... it is yeah; it is suitable and it is like more or less 60 to $70 \%$ of our way of applying in school." [Teacher B]. "Yes, I think that the SIOP method is not very different from what we are already doing in our school" [Teacher D]. "Yes, definitely since we do all of the components" [Teacher E].

On the other hand, three participants indicated that their classroom environment might not be suitable to implement the SIOP model. According, to participant G she declared that she needs more time to search about the SIOP model in order to decide whether it suits her classroom or not. Also, participant $\mathrm{F}$ explained that there are a number of practices need to be changed to be able to implement the model. As for participant $\mathrm{C}$ he indicated that, in order to implement the SIOP model the teacher have to start step by step; due to its detailed components.

"Well actually when I read more about it... I will know whether it suits our students or no." [Teacher G]". In general, yes and no, some of the practices need some sort of change..." [Teacher F]. "...it is very elaborated...I think the SIOP is very... well if it is... implemented gradually ...." [Teacher C].

Furthermore, the participants were asked if they think that the curriculum encourages them to implement the SIOP model. The participants generally agreed that there are no boundaries to implement the SIOP model in comparison to the curriculum they use in school. Moreover, the participants B, C, and E indicated that their school curriculum is suitable for the implementation of the SIOP model since they are already applying almost the same components.

"Yes sure... we have at school our own curriculum ... this is one of the advantages that we might apply the SIOP in our school." [Teacher B]. "Yes, we have to adapt the lesson to such kind of strategies; it is a must. Otherwise the lesson won't be complete. If it lacks one of these steps" [Teacher E].

The participants were asked to provide their own viewpoints about the implementation of the SIOP model and the extent to which it motivates the students to learn. The majority of the participants indicated their agreement to this statement where participant A said "Yes of course". Furthermore, participant B explained that the implementation of the SIOP model will motivate students to learn and added that this model is a well-organized model that allows students to think creatively. According to participant $\mathrm{C}$, if the teacher applied the SIOP model successfully, then yes, it will motivate students to learn and the reason why it shows that the teacher how to apply it in details. Moreover, participant $\mathrm{G}$ answered that the components of the SIOP model will motivate students to learn better.

"Actually yes... it has all the building blocks for the students to receive the best learning.... It is well knitted plan... it gives the chance for the student's creativity." [Teacher B]. "If we take it very seriously, yes of course... Because it is not only what the teacher is going to do but also how to do it..." [Teacher C]. "I think yes, from what you showed us how it is done, I think yes it will motivate them to learn" [Teacher G].

On the other hand, participant D believes that the implementation of the SIOP does not make any difference to what the teachers in her school are already applying.

"I do not think it will make a much difference compared to what we are already do" [Teacher D].

To add more, the participant was asked to declare their opinions regarding the enhancement of the teachers' proficiency level that the SIOP might offer. Five out of seven teachers indicated that it defiantly helps in enhancing the teacher's proficiency level. For example, participant D indicated that the reason why the model is very detailed. The other two teachers indicated that in order for the SIOP model to help in enhancing the teachers' proficiency level, teachers need to be trained to implement it perfectly first.

"... if you want to apply such a strategy, you need to give teachers the suitable training first" [Teacher B].

"Properly yes, if they are trained on it".

The researcher asked the participants whether they think that teachers have basic knowledge about the SIOP model or not. Their answers varied, for example, participant A indicated that teachers should follow such models otherwise according to her point of view then they are not considered as teachers. Moreover, participant D indicated that she did not hear about the SIOP model, yet she and her colleagues have applied it unconsciously. 
Similarly, participant B declared that he believes that all teachers have basic knowledge about the SIOP model, and when he was asked on a general scale, his answer was the same. Furthermore, participant E thinks that all the teacher in her school has basic knowledge, again when she was asked to generalize the idea, she answered that she has no clue about the other teachers.

"Of course, since they are teachers and follow up with the lesson plans either the SIOP or any other... If they are not aware of such type of the lesson plan at least, then they are not teachers" [Teacher A]. "In general, yes. I am talking about our school... I have friends in other schools and they are knowledgeable about strategies and ready to apply any strategy..." [Teacher B]. "... we use everything that is there... technically everything at least like 85, $95 \%$ of it. Yes, we do... you might say the SIOP and they would not know but if they see the template, they will say yes, we do all of that" [Teacher D]. "... I do not know about the teachers... all of the teachers in our school are qualified to do it" [Teacher E].

In contrast, participant $\mathrm{C}$ believes that teachers in general do not have basic knowledge about the SIOP model as for his case, it was the first time he knows about it. Moreover, participant F offered the same idea as participant C. Furthermore, participant $\mathrm{G}$ declared that she has never heard about the SIOP model.

"I do not think so... in the same time the other schools, I do not think they have any clue about it" [Teacher C]. "Teachers in general I do not think so because for me it was the first time. So I think it is not very popular" [Teacher F]. "I do not think I have never heard of it" [Teacher G].

Moreover, in order to investigate whether the participants have any knowledge about the SIOP model, they were asked if they have ever applied the SIOP model during their teaching carriers. The participants' answers varied, for instance; participant A, B, and D indicated that they did not apply the model itself, yet they applied almost similar concepts to the SIOP model. Participant C, considered the reflection of the model on one of his classes. Moreover, participant E declared that she applied the model previously.

"I applied similar templates and I already used to write or prepare my lessons in details..., I will consider using it" [Teacher A]. "...specifically no, but when you touch upon different issues there .... are 4 or 5 out of 8 which are applied in our school" [Teacher B]. "No, not the model itself but 80 to 70 of it. It is like if we are applying it without labeling it as the SIOP model". [Teacher D]. "I was thinking to... to reflect one of my classes on the SIOP model" [Teacher C].

However, participant $\mathrm{G}$ declared that she never used this model. Similarly, participant $\mathrm{F}$ indicated that he only heard of it during these weeks, yet he benefited from reading about it and hoping to apply it in the coming weeks.

"No, I just heard of it during these two weeks.... I benefited from it... I hope in the coming weeks that I will do so (applying the model) ..." [Teacher F].

\subsection{The Teachers' Willingness to Implement the SIOP Model}

\subsubsection{Analysis of Interview Data}

In the last section of the interview, the participants were asked if they considered the application of the SIOP model in the future. The participants' answers were as follows; participant A stated that she is willing to apply the SIOP model in the future since she applied several templates in the past. Participant B showed his excitement to the implementation of the SIOP model. Similarly, participant F indicated that he is willing to apply the model especially the new element expressed in it. Moreover, participant G declared that the SIOP model is a "very good" tool to be applied. As for participant E, she indicated that "We are already applying it".

"Yes, sure because; I have applied many different templates so it is not going to be a problem for me to apply such template as well." [Teacher A]. "For sure, yeah. At least the new ideas that were expressed there." [Teacher F]. "Yes, why not. ... this is a very good to try so why not." [Teacher G].

In contrast, participant D declared that the SIOP model is very detailed and its implementation might be time consuming for the teacher. As for participant $\mathrm{C}$, he indicated that he is willing to implement the SIOP model but if he will be teaching in another school, that model is already applied.

"The planning of the SIOP model is very detailed, it will take a lot of time for me... It is time consuming". [Teacher D]. "It depends in where I will work... But if I find a school that applies SIOP and they take it seriously, I think that school will be very ... prestigious one" [Teacher C].

Finally, the participants were asked if they were willing to participate if there was another SIOP workshop. All participants showed their willingness to attend another SIOP workshop, because they are eager to learn more about every recent method that might be helpful to enhance the educational process. Nevertheless, participant A 
showed some concerns regarding the online workshop where she emphasized that her attendance depends on the workshop to be a live workshop where she can see and interact with the trainer rather than attending an online workshop.

"If this workshop is going to be live, ... Yes, I will be interested" [Teacher A]. "Yeah sure, actually I am like somebody who likes to learn what is new and actually this is for the benefit not only for me but for the generations that we are teaching" [Teacher B]. "Yes, I will go for it... I discover a lot of things that I have heard or I have read them before but I didn't know what they are or I didn't know why they are here..." [Teacher C]. "Yes, of course. Because I think I benefited from the first one... I think it is a model that needs to be generalized..." [Teacher F]. "Of course, sure... we are trying to find anything new for them (students) that could encourage them to learn more" [Teacher G].

\section{Discussion}

The findings of the study indicated that the participants cover mostly all of the SIOP components during their classes. On the other hand, the study revealed some of the obstacles that might affect the teachers' implementations of the SIOP model such as the time and place. In this part, the researcher will discuss these results in relation to similar studies. The analysis of the data revealed the participants' willingness to the implementation of the SIOP model by referring to it during their interviews as a "very good," "love it," "new ideas", "allows creative thinking", and "is not going to be a problem". This finding is aligned with those found by Ray (2011) where the participants showed enthusiasm to implement the SIOP model in the future. Similarly, the participants in Vidot's (2011) study have expressed their preference to implement the SIOP model as well. This is also parallel to the findings of Meza's (2010) study where the researcher found that the teachers are willing to make the required changes to implement the SIOP model. Furthermore, the results of the present study indicated that six out of seven participants think that the implementation of the SIOP model will motivate the students to learn. Hence, this is similar to what Ray (2011) suggested in his study regarding the fact that most of the teachers agreed that the SIOP model improved the students' achievement.

Furthermore, the results indicated that the implementation of the SIOP model might help in enhancing the teachers' proficiency level from the participants' perspectives. According to Koura and Zahran (2017), this model helps to develop the teachers' teaching skills and self-efficacy. Moreover, the analysis of the collected data showed that the participants are aware of the SIOP components but not the model itself; hence, some of them declared that this is the first time they knew about the model. Likewise, Meza (2010) indicated that there are some teachers that heard about the SIOP, yet it never used it, others have never heard about it at all, and few of them applied only parts of the model.

Based on the analysis of the collected data, the majority of the participants indicated that their classroom environment is suitable and encouraging for the implementation of the SIOP model. This is also shown in Alfadda's (2020) study where she declared that the Saudi classrooms are beneficially equipped with technical and financial capabilities to implement the SIOP model. Moreover, Alfadda's (2020) findings showed that the teachers are qualified enough to implement the SIOP model. In contrast, two out of seven participants in the current study have suggested that teachers need to be trained in order to implement the SIOP model.

Finally, the current study's results showed that several participants are encouraged to implement the SIOP model. Yet, two of them revealed some concerns regarding the model implementation. These concerns lie in the fact that the model is a time-consuming one due to its detailed components and the other reason is the place they work in. Moreover, one participant showed some reservations regarding the school policy where he cannot implement the SIOP model. This might be similar to what Meza (2010) declared in her research findings that even if the teachers are aware of the benefits of the SIOP model yet, they feel that there is significant pressure on them if they decided to apply it since they have no time and they are not trained to use it by all means.

\section{Limitations of the Study}

The findings of this study have to be seen in the light of some limitations. As mentioned above, the study circumstances were conducted online which caused a lack of face-to-face communication. Another limitation is the short time the study was conducted in addition to the late response of the school's administration. Nonetheless, the study participants were only female/male English language teachers from one private school in Riyadh; this might limit the generalization of the study results compared to when the teachers were from different schools. Therefore, the study recommends a longtime study for future researchers, expansion of the number of participants, and doing a live sample workshop. 


\section{Conclusion}

This study examined the implementation of SIOP model in a private Model school in Riyadh from the perspectives of teachers. Based on a qualitative research design where the data was collected using an observation session and a semi-structured interview, the participants showed a significant application of the SIOP components in their lessons. Moreover, the interview results indicated that the implementation of the SIOP model might help in increasing the students' motivation to learn and enhancing the teachers' proficiency level. Furthermore, the study showed that the teachers' perspectives vary based on different reasons whether to implement the SIOP model or not. Furthermore, the study revealed that the SIOP model could be an effective tool in the educational process. However, the study reported that time and place might hinder the SIOP model's future implementation.

\section{Acknowledgment}

First and foremost, praises and thanks to God, the Almighty, whose mercy and blessings throughout my study have helped me to complete it successfully.

I would like to express my deep and sincere gratitude to my research supervisor Prof. Hind Alfadda whose advice, professionalism, knowledge and continues support had me towards finishing my study. Her dynamism, vision, and sincerity have deeply inspired me to become a better researcher. Also, her motivational words made me ambitious to complete this study and dream for more.

I am extremely grateful to my mother Haya Aldakhil for her love, prayers, caring and sacrifices for educating and preparing me for my future. I am thankful for every morning's goodbye prayers to school and university.

I am also thankful for my brothers and sisters. For my role model, big sister, and my companion on this journey Mada for her unconditional love, support, and advises. I am thankful for Abdullah who has tried his best to remove every obstacle that I face. I am also thankful for Hadeel for her ongoing love and support through listening to my complains yet never turned me down. My brother Mohammed for his love and precious smile that assures my soul. Thank you all and I love you.

I would like to thank my aunt Nora Aldakhil and her daughters, that I only see them as my sisters Hind and Safiah, for their love, support and prayers. Thank you.

Special thanks to my niece and nephew Leen and Ryan for their hugs, smiles, and joyful soul. I love you both to the moon and back.

Also, I would like to express my respect and gratitude for my family in law for their support and prayers, special thank you to my mother-in-law for her support and help when she takes care of my little angle Deem during conducting my study.

\section{References}

Al Fadda, H. A. (2020). Implementation of the Sheltered Instructional Observation Protocol (SIOP) Model in the Saudi Classroom: EFL Teachers' Perspectives. Arab World English Journal, 11(2), 339-360. https://doi.org/10.24093/awej/vol11no2.24

Alrashidi, O., \& Phan, H. (2015). Education Context and English Teaching and Learning in the Kingdom of Saudi Arabia: An Overview. English Language Teaching, 8(5), 33-44. https://doi.org/10.5539/elt.v8n5p33

Creswell, J. W., \& Poth, C. N. (2016). Qualitative inquiry and research design: Choosing among five approaches. Sage publications.

E Stake, R. O. B. E. R. T. (2010). Qualitative research.

Echevarria, J., \& Vogt, M. (2010). Using the SIOP model to improve literacy for English learners. New England reading association journal, 46(1), 8-15.

Echevarria, J., Richards-Tutor, C., Changes, R., \& Francis, D. (2011). Using the SIOP model to promote the acquisition of language and science concepts with English learners. Bilingual Research Journal, 34(3), 334-351. https://doi.org/10.1080/15235882.2011.623600

Echevarria, J., Short, D., \& Powers, K. (2006). School reform and standards-based education: A model for English-language learners. The Journal of Educational Research, 99(4), 195-211. https://doi.org/10.3200/JOER.99.4.195-211 
Echevarria, J., Vogt, M., \& Short, D. (2008). Making content comprehensible for English learners: The SIOP model. The International Journal of Learning: Annual Review, 14(11), 41-50. https://doi.org/10.18848/1447-9494/CGP/v14i11/45514

Fraenkel, J. R., Wallen, N. E., \& Hyun, H. H. (1993). How to design and evaluate research in education (Vol. 7). New York: McGraw-Hill.

Inceli, O. (2015). The perceptions of English teachers to the SIOP ${ }^{\circledR}$ Model and its impact on limited English proficiency. Journal of Ethnic and Cultural Studies, 2(1), 15-28. https://doi.org/10.29333/ejecs/13

Kareva, V., \& Echevarria, J. (2013). Using the SIOP model for effective content teaching with second and foreign language learners. Journal of Education and Training Studies, 1(2), 239-248. https://doi.org/10.11114/jets.v1i2.173

Laney, J. D. (2011). Sheltered Instruction: A Case Study of Three High School English Teachers' Experiences with the Siop Model (Doctoral dissertation, University of North Texas).

Linneberg, M. S., \& Korsgaard, S. (2019). Coding qualitative data: A synthesis guiding the novice. Qualitative Research Journal.

McIntyre, E., Kyle, D., Chen, C. T., Muñoz, M., \& Beldon, S. (2010). Teacher learning and ELL reading achievement in sheltered instruction classrooms: Linking professional development to student

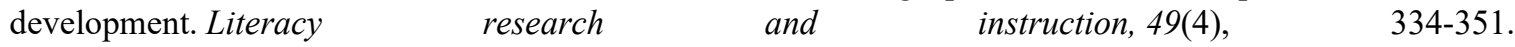
https://doi.org/10.1080/19388070903229412

Meza, D. (2010). English as a second language: The impact of teacher responsiveness to implementing the sheltered instruction observation protocol model. James Madison University.

Murillo, R., \& Alejandro, H. (2013). Adapting features from the SIOP component: Lesson delivery to English lessons in a Colombian public school. Profile Issues in Teachers Professional Development, 15(1), 171-193.

Otway, M. N. (2007). Teachers' practices, perceptions, and perspectives of instructing English language learners. Walden University.

Patton, M. Q. (2002). Two decades of developments in qualitative inquiry: A personal, experiential perspective. Qualitative social work, 1(3), 261-283. https://doi.org/10.1177/1473325002001003636

Salman, I. (2017). A Mixed-methods Study of English Language Learners' Academic Achievements in a Spanish Language Immersion School.

Short, D. J., Echevarría, J., \& Richards-Tutor, C. (2011). Research on academic literacy development in sheltered instruction classrooms. Language Teaching Research, 15(3), 363-380. https://doi.org/10.1177/1362168811401155

Short, D. J., Fidelman, C. G., \& Louguit, M. (2012). Developing academic language in English language learners through sheltered instruction. Tesol Quarterly, 46(2), 334-361. https://doi.org/10.1002/tesq.20

Short, D., \& Echevarria, J. (2004). Teacher skills to support English language learners. Educational leadership, 62(4), 8-13.

Song, K. H. (2016). Applying an SIOP-Based Instructional Framework for Professional Development in Korea. TESL-EJ, 20(1).

Valle, M. S., Waxman, H. C., Diaz, Z., \& Padrón, Y. N. (2013). Classroom instruction and the mathematics achievement of non-English learners and English learners. The Journal of Educational Research, 106(3), 173-182. https://doi.org/10.1080/00220671.2012.687789

Warschauer, M. (2000). The changing global economy and the future of English teaching. Tesol Quarterly, 34(3), 511-535. https://doi.org/10.2307/3587741

\section{Copyrights}

Copyright for this article is retained by the author(s), with first publication rights granted to the journal.

This is an open-access article distributed under the terms and conditions of the Creative Commons Attribution license (http://creativecommons.org/licenses/by/4.0/). 